\title{
Selected Reference Works, 2006
}

\section{Sarah Witte and Mary Cargill}

\begin{abstract}
This article follows the pattern set by the semiannual series initiated by the late Constance $\mathrm{M}$. Winchell more than fifty years ago and continued first by Eugene Sheehy and then by Eileen Mcllvaine. Because the purpose of the list is to present a selection of recent scholarly and general works, it does not pretend to be either well balanced or comprehensive. A brief roundup of new editions of standard works is provided at the end of the articles. Code numbers (such as AC527) have been used to refer to titles in the Guide to Reference Books, 11th ed. (Chicago: ALA, 1996).
\end{abstract}

\section{Periodical Indexes}

Dialnet [electronic resource]. [Logroño, Spain]: Universidad de la Rioja, 2001-. dialnet.unirioja.es. Free.

Dialnet greatly expands access to contemporary scholarly publishing in Spain. The database fills gaps left by better known periodical indexes and full-text products that provide only limited coverage of Spanish publications.

Formed in the spirit of the Open Access movement, Dialnet was launched in 2001 by the University of Rioja in Longroño, Spain, as a cooperative project of a network of Spanish academic libraries. In the five years since its debut, the database has grown steadily, incorporating new content and improving its interface and functionality. Dialnet currently provides access to the tables of contents of over 3,000 humanities, social sciences, and science journals published primarily in Spain and Latin America and includes over 1.2 million documents, approximately 100,000 of them in full text. (Part of Dialnet's mission is to help publishers by generating and hosting full-text editions of their publications.) In addition, six Spanish universities are making available the full-text versions of doctoral dissertations via Dialnet. The database also includes citations to articles published in edited books and has recently incorporated the full text of working papers from academic research centers in Spain and Latin America. An issue-alerting service is available via free registration, and coverage of back issues varies widely by title.

At this time, fourteen Spanish and one Chilean academic libraries participate in the production of Dialnet, and other Latin American libraries are expected to join the project in the near future. This expansion will increase coverage of resources from Latin American countries.

Following its November 2006 redesign, the Dialnet site provides a simple and clean

Sarah Witte and Mary Cargill are reference librarians in Butler Library at Columbia University; e-mail: spurgin@columbia.edu and cargill@columbia.edu. Although it appears under a byline, this list is a project of the reference departments of the Columbia University Libraries and notes are signed with the initials of one of the following staff members: Barbara Sykes-Austin, Avery Library; Seth Kasten, Burke Library; James L. Coen and Kathleen Dreyer, Business and Economics Library; Nancy Friedland, Anice Mills, Robert H. Scott, and Junko Stuveras, Butler Library; Pamela M.Graham, Latin American and Iberian Studies Librarian; and Bindu Bhatt, South Asian Studies Librarian. 
interface, available in Spanish or English. A document search option allows one to search words appearing the title or author fields, or in the abstract (but not within the full text of articles when available). It is also possible to browse journal issues, organized into thirteen major subject categories and further subdivided by topic. Entries for journals include basic bibliographic information, links to publishers' Web sites, a list of citations for all available articles organized by author, and links for viewing individual issues. Dissertations can be searched or browsed by topic in a separate section of the database. Dialnet is easy to use, but it would be helpful to include more background information about the project and explanations of the scope and coverage of the database.

Dialnet is a free service, but libraries contributing to the database can offer their users enhanced services, such as more advanced search options (limiting by language and/or date), information about local holdings, and the ability to manage and e-mail search results.

The lack of indexing of many of these Spanish publications in other major databases, and the limited and fragmented appearance of digital versions of such journals, mostly via publishers' Web sites, have been long-standing problems. Dialnet's strength and contribution have been to marshal the resources of academic libraries into expanding the visibility of scholarly Spanish publishing via a simple but functional database that serves as a freely available portal to this important research material. Highly recommended for academic and research libraries.-P.M.G.

\section{AIDA: Articoli italiani di periodici accademici}

/ Bibliography of Italian Periodical Literature [electronic resource]. $€ 957$ annual subscription (ISBN 3-5986913-8). K. G. Saur Verlag, dist. by Thomson in the United States. Www. saur.de. The database is hosted by GBV (Gemeinsamer Bibliotheksverbund). AIDA, which began as a CD-ROM database, is now available in a Web version.
It indexes more than 1,000 scholarly journals published in Italy and currently contains over 152,000 articles. Some 16,000 articles are added each year. There is an online list of journals indexed (www.saur. de/download/quellenlisten/0000010130. pdf). The current edition of the database covers articles published 1997-2006.

Both English and German are available as interface languages. Searching offers two modes: simple and extensive. The simple search has one search box, and search term(s) may be set to search any fields or a specific field: author, article title, journal title, corporate name, classification (subject terms), publisher, place of publication, year of publication, and ISSN. If you enter more than one term, a Boolean operator (and/or) can be selected from the drop-down menu. It is also possible to browse and select from a list of search terms. Search results may be sorted by relevance or date (most recent first). The extensive search mode can combine up to four sets of searches similar to the simple search by Boolean operators (and/or/and not) in addition to limiting the search by date. It also supports the use of wildcards: ? (any number of characters), \# ( maximum of one), ! (exactly one). More than one truncation symbol can be used in a single term. Proximity searches (near/n) are also available.

The user can review a search history of the session and can select and combine previous searches in a new search. Results may be e-mailed or copied to a separate window and then downloaded or printed. A page may be printed using the browser's print command. A nice feature is that it prints the main content only, skipping the sidebar and the top of the screen where the search box is visible.

In Germany, the database is linked to the online interlibrary loan and document delivery services of GBV. In the United States, the database can be e-link enabled.

Recommended for university libraries serving Italian-speaking readers. Even when a library subscribes to $I B Z, A I D A$ is a good supplement, because $I B Z$ is 
predominantly English (48\%) and German (39\%). Only $6 \%$ of IBZ is French, and all other languages, including Italian, amount to only $7 \%$. Although IBZ is a much larger database with an annual growth of 120,000 entries, AIDA has a certain advantage for scholarly Italian journals. - J.S.

\section{Biography}

Słownik biograficzny historii Polski. [Biographical Dictionary of Polish History.] Eds. Janina Chodera and Feliks Kiryk. Wroclaw: Zakład narodowy im. Ossolińskich, 2005. 2 vols. ISBN 83-04-04692-X.

Krystyna Jakowska. Podręczny słownik pisarzy polskich. [Concise Dictionary of Polish Writers.] Warszawa: Wiedza powszechna, 2006. 669p. ISBN 83-2141360-9.

The past two years have witnessed the appearance of two valuable Polish-language biographical references for scholars of the history and literature of Poland. While both were produced with a broader public in mind in their home country, they will be accessible in this country primarily to specialists (or others with knowledge of the language), all of whom will benefit from the comprehensiveness and authority of these works.

The more recent of the two, a dictionary of Polish authors, produced by the slightly more popular Wiedza Powszechna publishing house, is largely the work of a single scholar: Krystyna Jankowska, a Polish literary historian active over the last three decades and currently on the faculty of the University of Białystok. She has assembled here some 1,300 entries on Polish writers from the earliest times to the present (including living authors), active both in Poland and in the emigration. For the modern period, this includes only authors writing in Polish. (Thus, for example, one will not find here biographies of such Polish-based Yiddish authors as Isaac Bashevis Singer or Isaac Leib Peretz.)

For her selection of individuals to include in the dictionary, Jankowska was guided for the earlier periods by references in major works of literary history and for the the recent period either by references to authors in works of general literary criticism or by the size of printing of their works. A number of classic compendia for specific periods, such as Nowy Korbut, Piszarzy staropolskich, Wspótcześni polscy pisarze i badacze literatury, and Maty stownik pisarzy polskich na obczyźnie 1939-1980 also served as a guide in selecting and compiling the entries. (A fuller list is provided in the introduction to the dictionary.)

Along with the authors of prose, poetry, and drama, who are covered quite broadly, one finds a number of individuals characterized as "essayists" as well as a selected group of political writers. While the latter two groups add an enriching layer, it is harder to predict whom one will or not find in these categories.

Each entry begins brief biographical information (birth and death dates, education, any nonliterary profession, the date of their literary debut, collaboration with particular publications, membership in literary groups and organizations, literary prizes and awards, and, in the case of the most important writers, some additional detail). It is then followed with a brief interpretative characterization of the writer's work, major themes, place in Polish literature, etc. This in turn is followed by a classified listing of each author's works, usually limited to book publications.

Słownik biograficzny historii Polski is a product of the Polish Academy of Sciences Ossolineum publishing house and is the collective work of nearly 150 scholarly authors. Its intended audience is likewise the general public in Poland. It exists in the shadow of the more comprehensive and scholarly Polski słownik biograficzny (Guide AH279); but, given the projected completion date of 2030 for that work, the need for a comprehensive and authoritative $\mathrm{A}-\mathrm{Z}$ guide for current readers was clear. The product is at once less and more comprehensive than the $P S B$, since 
it includes fewer entries than the latter for the periods already completed (up through the letter $S$ at the time of publication of this work) but including entries for individuals who have yet to appear in the latter or who had died since the time of publication of the earlier volumes of the PSB. (Both works include entries only for individuals who are no longer living.)

The PSB was one obvious tool for selecting individuals to be included here, but a variety of specialized and regional dictionaries, as well as more modern tools such as the Polish Who's whos and even Wikipedia, also served as sources in originally identifying individuals, although the authors of the essays were expected to perform a thorough search of the literature before completing their entries.

The entries are considerably briefer than those of the PSB, and include only a biographical and analytical sketch, without any additional references or bibliography.

The result is nonetheless excellent, providing an authoritative and comprehensive reference to the key figures of Polish history (including many literary authors). Moreover, the shorter format is sometimes useful in eliciting a more explicit characterization of the significance of a particular individual than is found in the lengthier essays in the PSB.

Both of these are tools that any serious collection addressing Polish history and literature must own. Given their compactness, they are likewise something that many individual scholars would be well advised to acquire for their personal collections. Until we have a fully comprehensive Polish national biography print (and undoubtedly long afterward as well), these works are likely to be key components of any serious Polish reference collection. - R.H.S.

\section{Religion}

Encyclopedia of New Religious Movements. Ed. Peter B. Clarke. New York: RoutledgeCurzon, 2006. 686p. \$225 (ISBN 0-415-26707-2).
"New Religious Movements" (NRMs) is an umbrella term for a large number and wide variety of phenomena, which vary greatly, according to cultural contexts. The Encyclopedia of New Religious Movements describes the concept as having been "devised in the 1960s to describe the emergence of a vast number of what were widely perceived to be new religious and spiritual movements which were characterized by their unconventional symbols of the sacred, their novel understanding of the relationship between the religious and/or spiritual, and the psychological, their new interpretations of the transcendent, and the new principles of belonging to and/or membership of a religion or spiritual movement which they exposed" (p.413). The more than 400 entries, arranged alphabetically, include organizations, leaders, influences, and grouping categories of NRMs; coverage is international in scope. The range of topics includes such entries as "A Course on Miracles" (program based on a channeled text), "Age of Aquarius" (astrological concept), "Black Jewish Movements," "Branch Davidians," "Chinmoy, Sri," "Druidry," "Falun Gong," "Leary, Timothy," "Lord's Resistance Army," "Millenarianism," "Opus Dei," and "Scientology."

Articles are nonjudgmental and signed; most include brief bibliographies. The academic institutions or other organizations with which the writers are associated are, unfortunately, not included in the list of contributors or with their articles. The index is the kind that does help the researcher-reasonably comprehensive and consistent. Also useful is the entry under "Resource guide to NRM studies," by the authoritative American scholar, J. Gordon Melton, which provides an overview of the contemporary study of NRMs and a bibliographic essay on resources for further study. Readers with a reading knowledge of French, German, Italian, Spanish, Portuguese, or Japanese should be sure also to consult the entries under "Literature in French," "Literature in German," and so on, "on NRMs." 
The editor does not claim that the Encyclopedia is exhaustive but states that only examples of varieties of NRMs in different parts of the world are included, so we should expect that it would be less than complete; nevertheless, the choice of topics included (or not included) may sometimes surprise the reader. The book includes "United Church of Christ in Japan" (although this ecumenical joining of mainline Protestant denominations is neither new nor a movement), for instance, but no entry for Calvary Chapel Churches (a rapidly growing fellowship of churches that is comparatively new and is recognizable as a movement, although it is briefly mentioned in the "Vineyard Ministries" entry). Adherents of the Church of Christ, Scientist and the Church of Jesus Christ of Latter-day Saints might very well object to their churches being categorized as NRMs, as implied by the inclusion of entries for them in this work.

Libraries or individuals concerned about the \$225 price for this single-volume work may wish to purchase instead the Encyclopedia of New Religions: New Religious Movements, Sects and Alternative Spiritualities, edited by Christopher Partridge (Oxford: Lion, 2004), a well-received but less comprehensive, textbook-like work costing $\$ 59.95$. The alphabetic arrangement, bibliographies, and literature essays in the larger work, however, are useful for research and should be made available to readers if at all possible. - S.K.

\section{Literature}

Charpentreau, Jacques. Dictionnaire de la poésie. Paris: Fayard, 2006. 1173p. € 49 (ISBN 2213624852). LC 2006-446723.

This dictionary is about poetic forms and techniques, not about biographies of poets. A wealth of material is found in this one-volume dictionary. It cites a number of examples of poems to illustrate and explain varied styles, techniques, and forms of poetry. In addition to technical aspects of poetry, it discusses typical themes of poetry such as love, patriotism, religion, and politics, schools of poets, and "isms" such as Parnassians, Romanticism, Futurism, and Postmodernism. It covers French poetry from its beginning to the present, including foreign influences from Grecian odes to Japanese haikai. The book is indexed by personal names of poets, writers, musicians, painters, and some others.

In terms of content, this is a worthy addition to any library collections that serve French specialists. The presentation or the way the book is printed and bound is a problem. The book has extremely narrow margins all around and is printed in a very small font. The gutter is so narrow that it is practically impossible to rebind the book if it becomes necessary. The narrowness of margins unfortunately gives an odd, truncated appearance to the pages of the book. - J.S.

\section{Architecture}

Ching, Frank, Mark M. Jarzombek, and Vikramaditya Prakash. A Global History of Architecture. Hoboken: J. Wiley \& Sons, 2006. 800p. il. \$75.00 (ISBN: 0-471-26892-5; ISBN13: 978-0-47126892-5). LC 2005-034527.

The first historical architectural encyclopedia that usually comes into a librarian's mind when one is needed is Sir Banister Fletcher's A History of Architecture, now in its 20th edition but first published in 1896 (Guide BF255). It is presented in a conventional historical arrangement, in which the architecture of Egypt, the ancient Near East, Asia, Greece and the Hellenistic kingdoms comes first, because in the Western experience it did. The illustrations, black-and-white photographs and bold line drawings of elevations, sections, details, and plans are meant to instruct the reader on the architectural elements and the visual vocabulary of construction and period style. The editors of the 1996 centennial edition are world-renowned architectural historians: Dan Cruickshank, Andrew Saint, Peter Blundell Jones and Kenneth Frampton.

A Global History of Architecture takes a different approach. It is first and foremost 
chronological in a truly global sense. The Contents pages are arranged by dates or, as the authors call them, "timecuts" beginning in $3500 \mathrm{BCE}$, with 1,000-year increments until $1500 \mathrm{BCE}$, when the pace quickens to spans of 400 years (800 BCE, $400 \mathrm{BCE}, 0), 200$ years (200 CE to 1600), and 100 years (1700-1900), culminating in a final date of 1950 that includes the Postmodernism of the 1980s and 1990s, with the last chapter on globalization. Under each date in the Contents is the list of architectural sites, so that the reader sees in the first moment the process of an emerging built environment worldwide. Each timecut then begins with an introductory summary and, since "the globe does not really begin in the east or the west but can indeed be started and ended anywhere" (Pref., xiv), the map that follows each introduction lays out the continents in an accurate but unconventional fashion, so that one has to look carefully to recognize them. As the sites appear, and the adjacent page's timeline places them in a tighter chronological order, buildings, civilizations, and cultures begin to reveal themselves. The notion of "modern" is consequently experienced in every period.

The style of illustration chosen for this volume is quite different from that in Banister Fletcher. Even in the latest edition of that work, the graphical presentation is muscular, bold, forthright, still Victorian. This new survey uses Frank Ching's lighter, sketchier hand, with more grays than black, not altogether successful for the black-and-white photographs. A short "color portfolio" of 31 photographs is included at the beginning and underscores the emphasis on the monumental architecture that is the subject of this book (for vernacular architecture, see Paul Oliver's Encyclopedia of Vernacular Architecture of the World, 3v., 1997 [reviewed in this column Sept. 1998, v.59, n.5, p.471-72]. Subsections within each timecut discuss individual sites and/or regions, usually covering one or two pages, and have their own internal order based on events.
The final sections include a glossary of architectural terms, a bibliography of general sources, online resources and period-specific sources for each timecut, photo credits, and an index. The authors' credentials are nowhere listed; however, Frank Ching is a well-known writer and illustrator of books on architectural drawing; he and Vikramaditya Prakash are on the architectural faculty at the University of Washington. Mark Jarzombek is director of the History, Theory and Criticism program in the Department of Architecture at M.I.T.-B.S.-A.

Stern, Robert A. M., David Fishman, and Jacob Tilove. New York 2000: Architecture and Urbanism between the Bicentennial and the Millennium. New York: Monacelli Press, 2006. 1520p. il. \$100 (ISBN: 1580931774; ISBN13: 9781-58093-177-9). LCCN 2006-019842. "New York 2000 is the fifth and last in a series chronicling architecture and urbanism from the time of the Civil War, when the modern metropolis began to take shape, until the beginning of the 21st century when, with the September 11, 2001, attack on the World Trade Center, its fate was cast upon the stage of world history in a totally unprecedented way" (Introd.). The earlier volumes, published out of chronological sequence, include New York 1880 (published in 1999), New York 1900 (1983), New York 1930 (1987), and New York 1960 (1995). Each successive volume has grown in size, from 502 pages for the 1900 volume (which covers the period from 1890 to 1915) to 847 pages for 1930 (the interwar period), 1,164 pages for 1880 (the Civil War to the Gilded Age), 1,374 pages for 1960 (1941 to 1976), and the finale at 1,560 pages (1976 to 2000).

The volume (it could easily have been two) under review differs from its predecessors in that the date in its title marks the end of the period covered rather than its midpoint, and has added color reproductions of photographs, drawings, plans, and models to its earlier black-andwhite palette. Other than that, it follows 
closely the same pattern of organization as the others, with sections and chapters devoted to different areas of the city, a section each on interiors, photographic sources, notes (which are extensive and serve as the bibliography), and an index. The introduction is a collection of essays on topics particular to the period, and these can be fascinating, as, for example, are the sections on architectural critics, New York as depicted in movies and on television, and "Narcissistic New York."

The team of writers, changing slightly with each volume, has been led from the beginning by architect Robert A.M. Stern, Dean of the Architecture School at Yale, who maintains a highly successful professional practice in New York. In his role as architectural scholar and historian, he has produced not only the definitive encyclopedia of New York architecture and urbanism but, with his colleagues, has written essays on the city and its buildings that lead the reader from one neighborhood and development controversy to another. For, in addition to fact-finding, this book is a good read. And perhaps even a good cry: the volume opens with a twopage spread of the confetti-colored 2000 New Year's celebration in Times Square, and ends with a brief afterward on the attacks of September 11, 2001, and a poignant photograph showing the Tribute in Light that shines on that anniversary each year from the still-empty World Trade Center site. "After the attack on the Trade Center, the grieving city stumbled, but soon enough began to rebuild itself and move on. That story of the city's rebirth is for others to tell." - B.S.-A.

\section{Film and Television}

Emmons, Mark. Film and Television: A Guide to the Reference Literature. Westport, Conn.: Libraries Unlimited, 2006. 366p. \$40 (ISBN: 1-56308-914-9). LC 2005-034358.

Film and Television: A Guide to the Reference Literature is an essential volume for any college or university library supporting programs in film or television studies.
Intended as a starting point for research, it fills more than a decade-long gap in the reference literature by providing an updated and comprehensive bibliography for film and television studies' resources. Listings include print and electronic resource titles and Internet Web sites - a welcome addition.

The focus is on movies and television shows, including every aspect from how they were produced, the creative team responsible for development, the actors, content and distribution and exhibition, reviewers, critics, and scholars. Individuals, individual movies, and television programs are not covered. Coverage is international in scope, with a section on national cinema; however, only Englishlanguage materials are included.

Mark Emmons, a librarian at the University of New Mexico, compiled works from a variety of resources beginning with several of the major-but now dated-standard reference works on film. He worked primarily from reference collections at his home institution and the UCLA library. He initially approached the organization of the bibliography by sorting by Library of Congress Subject classification and checking against Worldcat.

With a few modifications, the result is a standard arrangement, including fourteen chapters ranging from indexes and bibliographies, general guides, dictionaries and encyclopedias, film and television filmographies, national cinemas, genres, portrayals, screenplays, filmmakers and filmmaking, industry and fans and audiences.

Users navigating through the 1,244 numbered entries are aided by a detailed table of contents, cross references, subject index, title and author index.

The work succeeds on many levels. The entries are well annotated, and the decision to include dated and still important works makes this a comprehensive volume on the literature. The sections on national cinemas, genres, studios, portrayals, filmmakers, screenplays, and industry are good and important to have 
in one volume. The Internet Web sites are highly selective and serve to question whether this volume should be available electronically or whether an additional index should have been provided separately listing Internet sites.

The sections on general resources are also good but not without a few puzzling entries. For example, movie review sources are not easily found from the table of contents. They are hidden in a category entitled "Collections and Cumulations," which is part of chapter four entitled "General Film and Television Filmographies." The user is better served by going to the subject index for review sources.

Overall, this is a welcome and timely addition to the reference literature. Highly recommended.-N.F.

\section{Gay and Lesbian Studies}

GLBT Life [electronic resource]. EBSCO Publishing. Price varies. www.epnet. com.

This important new database, which exists in two formats: GLBT Life and GLBT Life with Full Text, indexes and provides selected full-text access to both primary and secondary literature in gay, lesbian, bisexual, and transgender studies.

Libraries with comprehensive database collections will find considerable overlap in the coverage of scholarly periodical literature (title list: www.epnet.com/titleLists/qr-coverage.pdf), as many titles available here are also indexed in Women's Studies International, Gender Studies Database, ProQuest, Sociological Abstracts, in the other Ebsco databases, and in many other discipline-specific indexes. But readers will be thrilled to find these articles indexed together in a database with an easily identifiable title.

The strength of this database, however, is in its unique coverage of historical titles. GLBT Life indexes many of the important early gay and lesbian periodicals, including: ONE (1953-1967), The Ladder (1956-1972), Mattachine Review (1955-1964), The Advocate (1966-present) Christopher Street (1976-1995), Body
Politic (1971-1987), The New York Native, 1980-1997), and much more. Most of these earlier titles are not available in full text, but the indexing alone is invaluable. In all, some 120 contemporary and historical GLBT periodicals are indexed.

GLBT Life also provides indexing and abstracting for some 230 books and reference works, with the full-text version of the database linking to the full text of chapters and encyclopedia entries.

The database is easy to use with the standard Ebsco features. It can be used with sfx and other linking software.

GLBT Life is an expensive database, especially compared to Sexual Diversity Studies, which it absorbed in 2005. But it uses the Carnegie institutional classification system to set tiered prices by size of institution. In addition to the cost, many libraries may discover that GLBT Life uncovers some holes in their collection. As institutions turn to some of the new collections of microfilmed GLBT periodicals, it is hoped that GLBT Life will continue to index more and more of these periodicals from the seminal years of the gay and lesbian movement.-S.W.

\section{Folklore}

Greenwood Encyclopedia of World Folklore and Folklife. Ed. William M. Clements. Westport, Conn.: Greenwood, 2006. 4 vols. \$449.95 (ISBN 0-313-32847-1). LC 2005-019219.

While there have been a number of different dictionaries or encyclopedias of folklore, dating back at least to the classic Funk \& Wagnall's Standard Dictionary of Folklore, Mythology, and Legend (Guide CF51), these works have varied widely in scope and character. Nor has there been any single work to which a researcher could confidently turn in search of information on the folklore of any given part of the world. Part of the reason, perhaps, has been the elusive character of the subject itself: the aforementioned Funk and Wagnall work, for example, provides some 21 different definitions of the term, and one of the authorities cited 
in that entry notes that "folklore" in the collections and works of preceding eras had in fact meant "pretty much what any author wanted it to mean." Another reason has probably been the localized, scattered, uneven, and ever more distant character of folk culture, associated as it is with traditional societies and ways of life that find themselves increasingly overwhelmed, to varying degrees, in a globalized, industrial, and post-industrial world. In any case, looking at the body of literature to date, one finds the tag of dictionary or encyclopedia of folklore applied with equal measure to listings of folk tales, dictionaries of superstitions, catalogues of myths, and compendia of information about the concepts involved in the study of folk culture. Moreover, most of those works have been fairly uneven in their coverage, with the greatest wealth of material devoted to European and North American phenomena. In most cases, too, the entries in those works have tended to be relatively brief, restricted to a glossary-like, rather than encyclopedialike, treatment of their subject.

The work under review here sets out in an ambitious and promising new direction, with 205 articles by 205 scholarly specialists aiming at a far lengthier and more comprehensive coverage of particular cultures than has heretofore been available, in an attempt "to survey the world's folklore heritages in a way that emphasizes the international nature of folklore in general and of specific folklore materials, while placing folklore within particular cultural milieus." In the view of advisory editor Thomas Green, this project provides an opportunity to build on his own earlier Folklore: An Encyclopedia of Beliefs, Customs, Tales, Music, and Art (Santa Barbara: ABC-CLIO, 1997), a work that provided the lengthier scholarly treatment for a more general consideration of the forms, methods, and theories of folklore studies. However, as he notes, that work, with its more synthetic approach, took the folkloric material out of its original cultural context. This new encyclopedia, however, helps to make up for those earlier omissions by providing detailed characteristics of individual cultures and offering an opportunity for a comparative analysis of folk creativity around the globe.

Ironically, the editors of this work nowhere provide an explicit definition of their own understanding of the word "folklore." Implicitly, however, they seem to embrace a very broad conception of the term, one embracing the whole range of the customary cultural output of traditional, preliterate, preindustrial societies (and their continuing survivals in an era of literacy and industry). Contributors writing on specific cultures were asked to address a broad range of phenomena in their countries or groups: traditional belief systems (including medical practices as well as worldview and religion), verbal art, music and dance, sports and games, and graphic and plastic arts. To set this cultural output in a broader social frame, they were likewise asked to consider treatment of geographical setting, relevant sociocultural phenomena, ethnohistorical information, and the effects of modernization and globalization.

The work begins with a collection of forty essays on some general topics and themes, ranging from methodological essays such as "Bibliography" and "Fieldwork" to general interpretative questions such as "Diffusion" and "Race" to recurrent motifs such "Hero" and "Trickster." The material presented here is interesting, but it is not extensive enough to supplant the earlier work of the aforementioned Folklore, which researchers will also want to consult for more theoretical treatment of topics. The Greenwood encyclopedia really comes into its own when it turns to the treatment of specific countries, peoples, and groups, divided regionally among the four volumes in the set as follows: 1) Africa, Australia, and Oceania; 2) Southeast Asia and India, Central and East Asia, Middle East; 3) Europe; 4) North and South America.

The content of this survey is most impressive. Substantive essays of 3,000 
to 5,000 words each devoted to specific countries or ethnic groups (with longer treatments for some major countries) provide an excellent introduction to those new to the study of folklore and a useful summary for more advanced scholars as well. The contributors to articles on individual cultures generally make an effort to cover the range of topics outlined above and usually end their treatment with a brief but helpful bibliographic essay and a bibliography of key works, including titles in foreign languages. The structure of the more general topical entries at the beginning of the first volume differs slightly, but those entries include a list of key bibliography as well.

Throughout the work, maps identify the location of the peoples and countries surveyed, particularly useful as the specific geographic location of many of the ethnic groups may not be familiar to the average reader. A geographical listing of the cultures at the end of volume four seeks to serve much the same purpose. That volume also contains a comprehensive list of the contributors and their academic affiliations. A cumulative index to countries, peoples, persons, and many major topics appears at the end of each volume (a laudable practice worth imitating in other multivolume reference works as well).

Altogether, this encyclopedia represents a major new step forward for folklore studies. It clearly belongs in every collection aiming to give serious treatment to world cultures, and, despite its price, it seems likely that many individual folklorists and anthropologists will want to add it to their personal collections. That said, the work leaves one hungering for more and represents but a first stage in an ongoing process of treating this issue. The editor notes that as many cultures as "feasible" were included, and it would be unfair to suggest that every world culture could have been given full treatment in this work. Nonetheless, there are some surprising or frustrating gaps in the collection. Introductory essays at the beginning of each volume would have been a useful way of identifying what had been left out and of describing how those omitted cultures related to the others. The volume on Europe, for example, had it included just eight more articles, could have offered reasonably comprehensive coverage of that continent, and it is unclear what, other than the ability to line up contributors in time, can explain the omissions. ${ }^{1}$ The lack of treatment for the Arab culture of any countries other than Lebanon, Palestine, and Yemen is also a striking shortcoming, as is the absence of entries on any of the major peoples of mainland Southeast Asia other than the Malays. Finally, while the North American volume contains a number of excellent essays on North American Indian groups, and on African Americans and Appalachia, there is no attempt to treat the-admittedly complex-issues of the folklore of any of the other immigrant groups who make up the bulk of the American population.

Likewise, while the index is extensive, the editors' vision of a comparative examination of world folklore could have could have been more fully realized by an even more detailed and comprehensive treatment, pointing readers to the treatment of even more parallel phenomena in the detailed individual essays.

However, neither of these minor criticisms should detract from the essential achievement of this pathbreaking new work. If anything, one simply hungers for more of the same, perhaps in a supplementary volume or even a second edition. And there may be another solution as well. This encyclopedia, along with The Greenwood Encyclopedia of African American Folklore, The Greenwood Library of American Folktales, and a number of other resources, has been made available online as World Folklore and Folklife (www.greenwood. com/dailylife/folklore_info.aspx) as the latest addition to Greenwood's Daily Life Online family of reference databases. Ultimately, the online format may provide the best setting for moving toward fully 
comprehensive treatment, permitting the fullest comparative perspective, and maintaining the currency of this powerful new reference source. - R.H.S.

1. It might also have been more sensible to include diaspora groups such as the Sepharadim, Ashkenazim, or Roma in a separate category, rather than applying them to particular regions - the Iberian peninsula for the first and Eastern Europe for the latter two-which really distorts their role in the European cultural milieu. Furthermore, the regional divisions provided in that volume for the Eastern half of Europe are not particularly useful or accurate in their groupings of cultures; this reviewer, in any case, would have wanted to distinguish the peoples of the Balkan peninsula from the Eastern Europeans of the former Soviet Union, and would have put Poland (and even the Baltic nations) in the Central European group along with the much more closely related cultures of Hungary, Slovakia, and the (absent) Czech nation, rather than Eastern Europe.

\section{Business and Economics}

iRatings [electronic resource]. Innovest Strategic Value Advisors. Price varies. www.innovestgroup.com.

iRatings is a global database that provides access to Innovest's proprietary company ratings, sector reports, weekly stock monitors, screening services and other research materials. Innovest analyzes a company's performance on value factors such as environmental, social, and strategic governance management, and how such factors impact competitiveness, profitability, and share price performance

$i$ Ratings contains industry and company reports on several thousand companies. The reports cover the industry's or company's investment risk based on its social, environmental, and corporate governance ratings. Innovest also provides documentation on its rating methodology

$i$ Ratings has an intuitive user interface database; little instruction is needed to use this product. The search interface includes screening on rating, country, and industry. The data is well organized and easy to find and understand. This database is a reliable resource for social responsibility ratings and research. It is recommended for large colleges and universities. - K.D.

Stefanini, Filippo. Investment Strategies of

Hedge Funds. Hoboken: Wiley, 2006.

315p. il. \$80 (ISBN 0470026278; ISBN-

13: 978-0470026274). LC 2006-016527.

The author's stated goal is "to help readers to understand in detail the investment behavior of hedge funds." There is no intention to give investment advice of any kind, or to promote particular funds, "but rather to describe how hedge fund managers make a profit, and sometimes suffer a loss, following a market uncorrelated approach."

The author is chief investment officer of an alternative investment company that specializes in managing funds of hedge funds.

Seventeen chapters comprise the work, from the first, which is an overview and description of the operating environment, to the last, which is a brief conclusion.

In between, the chapters address strategy history, strategy's theoretical description, descriptions of securities and their markets, hedging techniques and possible use of derivatives, some trading examples, liquidity, leverage, and risks and risk management.

Each chapter provides comprehensive coverage of its topic. For example, Chapter 10 on distressed securities includes a history of distressed securities, a description of the distressed debt market, an explanation of bankruptcy laws, a fourpart discussion of strategy, an analysis of strategy's historical performance, and remarks on risk.

Throughout the text are illustrations and charts, bibliographic footnotes, and inserted descriptions of real-world examples of the points under discussion. There is a two-page bibliography appended and a brief list of relevant Web sites. This work is recommended for professional or graduate-level collections.-J.L.C.

\section{History and Area Studies}

Encyclopedia of India. Ed.-in-chief, Stanley 
A. Wolpert. Detroit: Charles Scribner's Sons, Thomson Gale, 2006. 4 vols. il. $\$ 475$ (ISBN 0684313499 set). LC 2005019616.

Edited by Stanley Wolpert, Professor Emeritus of History at the University of California at Los Angeles, a respected scholar of South Asian Studies, this encyclopedia is a timely publication. India, the world's largest democracy, with the world's second highest population, is generally not very well understood. This encyclopedia tries to make it more understandable and gives the reader the chance to explore its past as well as its position in the present position in the global economy of today. The topics covered are as diverse as Aryabhatiya, Bindusara, Sonia Gandhi, Mohini Attam, Ajanta, Jainism, Step Wells, Public expenditure, Relations with USA, etc. Many scholars from around the globe have contributed to the nearly 600 articles in this four-volume set. The subjects include contemporary facts, history, geography, economics, arts, culture, defense, human rights, industrial growth, the judicial system, education, medical science, nuclear programs, politics, religion, secularism, theater, trade, and women.

Every article is signed and has a bibliography and cross-references. The entries are arranged alphabetically. The work includes a selected annotated bibliography, list of primary source documents, a glossary, and a comprehensive index. The entries are made more useful by inclusion of charts, maps, and photographs. The chronology of all major South Asian countries is included.

I was happy to note that cross-references in the index are made from newer names of cities to the older names (e.g., Mumbai: see Bombay). The map of India has been represented fairly by showing disputed boundaries appropriately with reference to the state of Jammu and Kashmir. Though expensive, it is worth it, as it makes a good source of an entry point for anyone interested in the study of India.-B.B.
Encyclopedia of the New American Nation: The Emergence of the United States, 1754-1829. Ed.-in-chief, Paul Finkelman. Detroit: Charles Scribner's Sons, Thomson Gale, 2005. 3 vols. il. \$395 (ISBN: 0-684-1346-4). LC 2005-017783. This handsomely designed encyclopedia focuses on the specific period from 1754 to 1829 in American history, a period of enormous geographic, economic, and political growth. It will provide students and researchers a wealth of information as they begin exploration of this "founding period of the United States," from the start of the Seven Years' War to the inauguration of Andrew Jackson. Arranged in three volumes, each of the 667 entries is signed and offers cross-references and a bibliography of further readings. A directory of contributors comprising scholars from across the country is listed at the end of the set.

Encyclopedia entries range across topics as varied as Attitudes Toward Nature to Gambling to Revivals and Revivalism. Access is provided alphabetically in the table of contents as well as via a synoptic outline at the end of the third volume that "provides an overview of the conceptual scheme" of the work. This is followed by a full-set index. A chronology highlights the main events of this 75-year period and provides historical context. While some entries are brief, others are treated in more detail. The 55-page section on American Indians, for example, includes an overview and nineteen separate articles, covering, among other things, demography, ethnography, religion, and resistance. Accompanying reproductions of paintings, lithographs, maps, and artifacts enhance one's understanding of the topic.

This encyclopedia is the last in the series of four Scribner encyclopedias that cover American history from the "first European exploration of the New World to the beginning of the twenty-first century." (pref.) Taken together, they cover seminal events, trends, and social and cultural changes that depict the development of the nation. 
Well written and augmented by wellchosen paintings, photographs, maps, and engravings, this encyclopedia explores the evolution of the United States in a formative time. Its comprehensive and interdisciplinary approach makes it a valuable addition to reference collections in academic libraries serving undergraduates and more advanced researchers alike.-A.M.

\section{New Editions, Supplements, etc.}

A number of new editions of old standards have appeared recently, including the second edition of The Encyclopaedia Judaica (New York: Macmillan Reference, 2006. 22v. \$1995; 1st ed. 1971-72. Guide BC546). Nearly half of the original articles have been updated and revised, and some 2,600 new ones have been added; in addition, all of the bibliographies have been updated. It is also being published in an online version. The sixth edition of the always useful Famous First Facts (New York: Wilson, 2006. 1,300p. \$185; 1st ed. 1933. Guide AB106) has added some 1,000 new entries in the areas of science and technology, military history, and politics and has updated older entries. The Oxford Companion to English Literature is also now in its sixth revised edition (New York: Oxford, 2006. 1184p. \$60; 1st ed. 1932. Guide BE610). The revisions include updating the chronologies and the lists of prize winners, as well as updated entries.

Other new editions in the literary field include the second edition of The Encyclopedia of Language and Linguistics (Amsterdam: Elsevier, 2006. 14v. \$5600; 1st ed. Oxford: Pergamon, 1994. Guide BD34). This is actually, according to the introduction, a new work, "with new and expanded sections, new topics, new authors, and newly commissioned articles," though it retains the first edition's focus on both the scientific study of languages as well as linguistic theory. It is also published in an online version, which "supplements the written text with additional illustrative material that is only possible in an electronic version-samples of spoken or signed languages, videos on the use of language in context, and the like."

The third edition of The Cambridge Guide to Literature in English (New York: Cambridge, 2006. 1241p. \$50; 1st ed. 1988, Guide BE608) attempts a broader coverage than The Oxford Companion to English Literature, since it includes information on writing from the entire English-speaking world. The new edition has updated its entries for living authors, adding some 280 new listings.

The second, revised and expanded, edition of Lawrence Green's and James J. Murphy's The Renaissance Rhetoric Shorttitle Catalogue 1450-1700 (Aldershot, England; Ashgate, 2006. 467p.) is an expanded version of James J. Murphy's Renaissance Rhetoric: A Short-title Catalogue of Works on Rhetorical Theory from the Beginnings of Printing to A.D. 1700 (New York: Garland, 1981. Guide BE360). The new edition provides "a comprehensive list of primary printed sources for the study of Renaissance rhetorical theory in Europe and America," arranged by author, with holdings in a "small number of major libraries," including major British and French libraries and the Huntington Library. The compilers hope to provide indexes of places and publishers at a later date.

Elizabeth Knowles has compiled a second edition of The Oxford Dictionary of Phrase and Fable (Oxford: Oxford Univ. Pr., 2005. \$40. 1st ed. 2000). There are fewer biographical entries but more extensive coverage of the meanings and origins of the phrases.

In the vast and growing field of popular culture, the tenth, corrected and augmented, edition of Félix Coluccio's Diccionario Folklórico Argentino (Buenos Aires: Corregidor, 2006. 1089p.; 1st ed. 1948) has been published. The second revised edition of Myron J. Smith's The Baseball Bibliography (Jefferson, N.C.: McFarland, 2005. 4v. \$150; 1st ed. titled Baseball: a Comprehensive Bibliography, 1986, and Supplement, 1993, Guide BK60) now contains some 57,000 entries on the 
sport ranging from ESPN: The Magazine to doctoral dissertations.

The History Highway: A 21st Century Guide to Internet Resources (Armonk, N.Y.: M.E. Sharpe, 2006. 682p. \$34.95; 1st ed. The History Highway: a Guide to Internet Resources, 1997) offers "detailed information about thousands of quality resources." A section on evaluating Internet resources has been added.

Research on Africa is aided by Hans Zell's fourth revised and expanded edition of The African Studies Companion: A Guide to Information Sources (Locharron: Hans Zell, 2006. 833p. \$300; 1st ed. 1989, Guide DD 55). This has an extensive section on online as well as print resources and a list of African studies organizations and programs. Purchasers of the print version will automatically get access to the regularly updated online version. John Stewart has compiled the third edition of African States and Rulers (Jefferson, N.C.: McFarland, 2006. \$115; 1st ed. 1989), which updates the lists of rulers through late summer 2005.

The Oxford Companion to the Garden, edited by Patrick Taylor (New York: Oxford Univ. Pr., 2006. 554p. \$65), is a new edition of the 1986 Oxford Companion to Gardens (Guide BF290). It aims to present "a clear idea of the sort of gardens made in those countries in which gardening has been a significant ingredient of the culture" and has expanded its coverage of Eastern Europe, parts of the Middle East, and China. British architectural historian James Stevens Curl has com- pleted the second edition of his concise but scholarly Dictionary of Architecture and Landscape Architecture (New York: Oxford Univ. Pr., 2006. 880p. \$45; 1st ed. 1999). Cyril M. Harris has published the 4th edition of his essential Dictionary of Architecture $\mathcal{E}$ Construction (New York: McGraw-Hill, 2006. 1,089p. \$74.95; 1st ed. 1975. Guide BF242) and has added another 100 illustrations and some 2,500 new terms.

Volume 11 of the Encyclopedia of Indian Philosophies (Delhi: Motilal Barnarsidass, 1970-. Guide BB33), covering Advaita Vedānta from 800 to 1200 A.D., was published in 2006; it continues volume 3 of the set, which covers Advaita Vedānta up to 800 A.D. Volume 1, A-Del, of Brill's New Pauly: Encyclopaedia of the Ancient World. Classical Tradition (Leiden: Brill, 2006-; to be in 5 vols.) continues the English translation of Der Neue Pauly: Enzyklopädie der Antike (Stuttgart: J.B. Metzler, 1996-2003. 16v. in 19). The volumes in the Classical Tradition deal with the aftermath of antiquity and continue Brill's New Pauly: Encyclopaedia of the Ancient World: Antiquity (Leiden: Brill, 2002-), which will appear in fifteen volumes. Volume 9, Mini-Obe, was published in 2006.

Even in this era of online material, detailed indexes are still useful, especially for full-text material; fortunately, Byron Falk is still issuing his Personal Name Index to "The New York Times Index" (Guide AE108). Volumes 1-2 (A-C) of the 1975-2003 supplement were published in 2006.-M.C. 


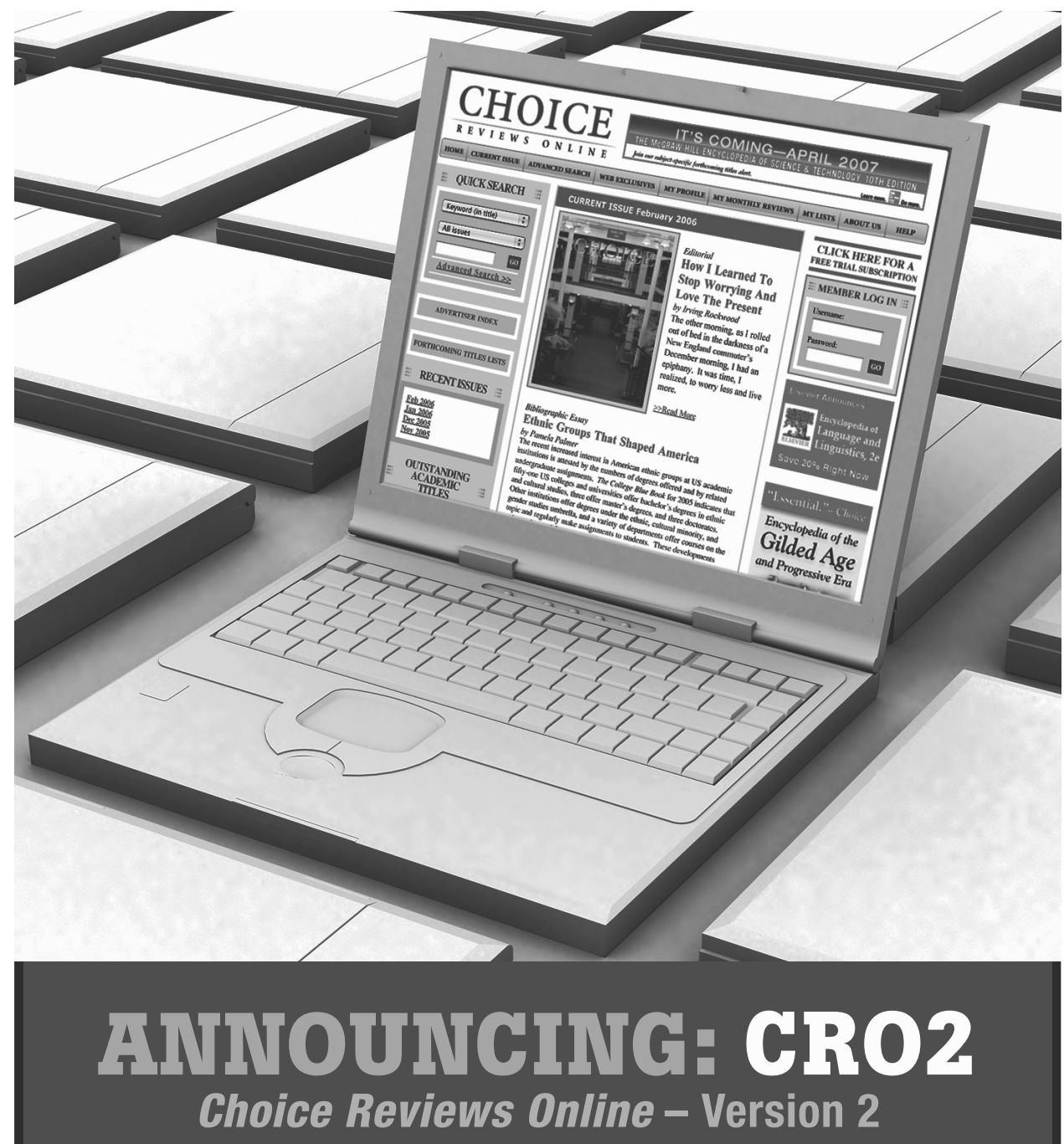

Comprehensive Content

115,000 Searchable Reviews

Enhanced Search Capabilities
Improved Interface

More Personalization

Web Exclusives

CR02 will replace both the Password and Site License Editions of -

ChoiceReviews.online, combining the best features and functions of both versions! -

FOR MORE INFORMATION VISIT WWW.GRO2INFO.ORG 